Review Article

\title{
Optimisation Techniques for Location of Flexible AC Transmission System Devices in Power Systems
}

\author{
Noor Izzri Abdul Wahab, Suleiman Musa, Rebaz J. Ahmed and Halimatusaadiah Bt Rusli
}

Department of Electrical and Electronic Engineering, Faculty of Engineering,

Universiti Putra Malaysia, 43400 UPM Serdang, Selangor, MALAYSIA

Received 20 July 2012; Accepted 25 November 2013

\begin{abstract}
Flexible AC Transmission System (FACTS) devices are the key to produce electrical energy economically and environmental friendly in a deregulated market. Implemented through a new equipment consisting high power electronics based technologies, it opens up new opportunities for controlling line power flows, minimizing losses and maintaining bus voltages at desired level in a power system network. In large, interconnected power systems, power system damping is often reduced, leading to lightly damped electromechanical modes of oscillations. Proper controller design and installation of this system becomes essential for control and operation improvement of power systems networks. Three categories of FACTS controllers may be distinguished: Series controllers; Shunt controllers; Combined series-shunt controllers. The location of these devices depends on the amount of local load and through load and from transient stability point of view their location moves towards the sending-end. The optimal location for the device is not in the mid-point of the line but rather, slightly off-center of the transmission line gives better performance for maximum benefit and depends on the line resistance and is linearly increased as $\mathrm{R} / \mathrm{X}$ ratio of the line is increased. The paper attempted to highlight best location and control strategy for this device that, guarantee security and stability of the power system networks for maximum benefits.
\end{abstract}

Keywords: Facts devices, optimization technique, transmission system and controllers

\section{Introduction}

The need for more efficient and fast responding electrical systems has given rise to a new technology in transmission, base on solid-state devices. These are called Flexible AC Transmission Systems commonly abbreviated as FACTS, which enhance stability and increase line loadings closer to thermal limits. It is a new technology that perform the same functions as traditional power system controllers such as phase shifting transformers, transformer tap changers, passive reactive compensators, synchronous condensers, etc.[1][2]. Precisely FACTS devices allow the control of all parameters that determine active and reactive power transmission to include node voltages magnitudes and angles and line reactance [3]. It involved semiconductor switches which allowed much faster response times without the need for limiting number of control actions when compare with mechanical switching [2]. However, the technology is much more expensive than the mechanical one [4], and in three categories of FACTS controllers which may be distinguished: Series controllers; Shunt controllers;

* E-mail address: izzri@eng.upm.edu.my ISSN: 1791-2377 @ 2013 Kavala Institute of Technology. All rights reserved.
Combined series-shunt controllers [5]. This technology started with thyristor valve, and now uses Voltage Source Converters (VSC) which offers faster control over a wider range [6].

Among the important benefits of utilizing FACTS devices in electrical transmission systems include providing a Better utilization of existing transmission system assets, increased transmission system reliability and availability, increased dynamic and transient grid stability and reduction of loop flows [7] and [8].The amount of power generated from renewable energy source integrated into large scale power systems forms only a small part of the total Electrical power generation. Most of the electricity supply is still being generated by conventional sources, such as thermal, nuclear and hydro generators. Thus, the requirement for voltage and frequency support largely depends on this conventional form of generation. Under large disturbance, such as a grid fault, the power from the renewable sources is rapidly disconnected from the power network and reconnected when normal operation is restored. Moreover, due to growing energy demands and limited resources, the power industry is facing a lot of challenges on the electricity infrastructure. Therefore it becomes necessary to require renewable sources for continuous operation during grid disturbances and 
thereby providing support for the network voltage and frequency [9]. Some of the commonly used devices for this support is the FACTS devices which include: Static synchronous series compensator (SSSC), static synchronous compensator (STATCOM), interline power flow controller (IPFC), unified power flow controller (UPFC) and thyristor controlled series compensator (TCSC) [10], [11] and [12]. Ideally these controllers should be connected to the power system in a proper way because improperly placed controllers fail to produce optimum performance and can even be counterproductive, that's why the placement of these devices is of a great importance. Connecting shunt FACTS device at the mid-point of a line, for example gives the maximum benefit to the line. This was based on the simplified model of the line neglecting the resistance and the capacitance of the line. In this review, attempt is been made to explore the best location of the FACTS on the transmission line for optimum performance on the network.

\section{Facts Controllers}

The FACTS controller provide a new platform in the control of line power flows, minimizing losses and maintaining bus voltages at desired level in a power system network. These can be achieve by controlling one or more of the interrelated system parameters including current, voltage, phase angle, series impedance, shunt impedance, etc. with the insertion of facts controllers in a power system network. Through these devices the control of active and reactive power flow and the bus voltages can be done easily. There are many types of facts devices that have been invented and practically applied to the power systems. The applications of each of these controllers are different. They can be classified according to the way they are being connected to the network. They can be connected to the power system in series, shunt or a combination of series and shunt as mention earlier in the introduction. For series connected controllers there are: Static Synchronous Series Compensator (SSSC), Thyristor Controlled Series Capacitor (TCSC), Thyristor Controlled Series Compensation (TCSC), Thyristor Controlled Series Reactor (TCSR), Thyristor Switched Series Capacitor (TSSC), Thyristor Switched Series Compensation (TSSC) and Thyristor Switched Series Reactor (TSSR). For shunt connected controllers: Battery Energy Storage System (BESS), Static Synchronous Compensator (SSC Or STATCOM), Static Condenser (Statcon), Static Synchronous Generator (SSG), Static Var Compensator(SVC), Static Var Generator Or Absorber (SVG), Static Var System (SVS), Superconducting Magnetic Energy Storage (SMES), Thyristor Controlled Braking Resistor (TCBR), Thyristor Controlled Reactor (TCR), Thyristor Switched Capacitor (TSC), Thyristor Switched Reactor (TSR) And Var Compensating System (VCS). As for combined shunt and series connected controllers: Interphase Power Controller (IPC), Thyristor Controlled Phase Shifting Transformer (TCPST) and Unified Power Flow Controller (UPFC). The devices that are of a great deal and widely available commercially, which are seen in many literatures are: SVC, TCSC, UPFC, TCPST, and STATCOM. [13]

Among the FACTS controllers, Unified Power Flow Controller (UPFC), is the most complete. It is capable of utilizing three basic electrical system variables [11] line voltage, line impedance, and phase angle, that determine the transmitted power. The throughput active and reactive powers can be control independently by the UPFC. The versatility afforded by the UPFC makes it a prime contender to provide many of the control functions needed in solving a wider range of dynamic and steady-state problems encountered in electrical power networks [14][15][16].

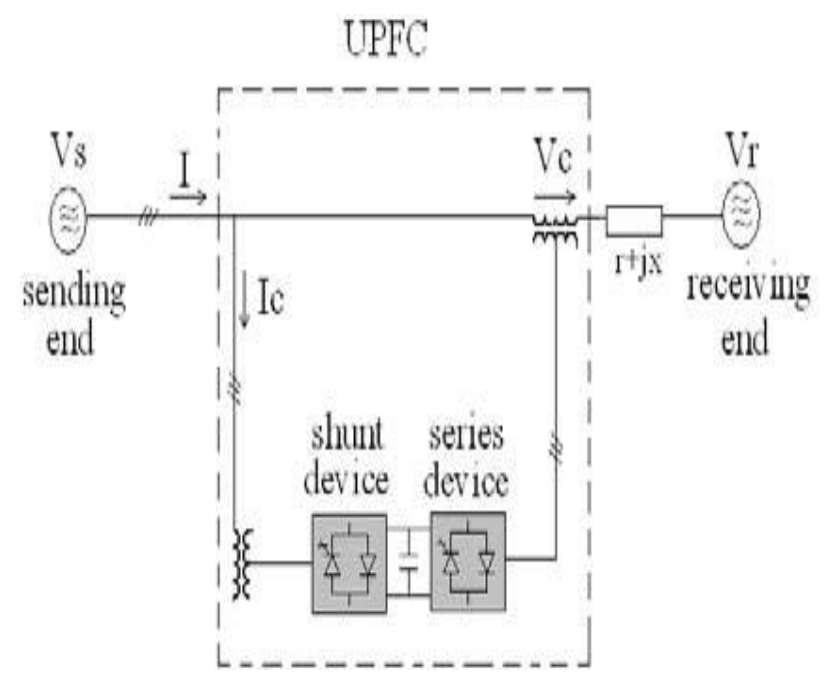

Fig. 1. UPFC Link in Transmission line

Two voltage source inverters (VSIs) form the basic components of the UPFC. They are sharing a common dc storage capacitor [17], and connected to the power system via coupling transformers. One VSI is connected to in shunt to the transmission system through a shunt transformer, while the other one is connected in series via a series transformer. A basic UPFC functional scheme is presented in fig. 1 .

The series inverter is used to inject a symmetrical three phase voltage system $\left(\mathrm{V}_{\mathrm{c}}\right)$, of controllable magnitude and phase angle in series with the line to control active and reactive power flows on the transmission medium. The reactive power is electronically produced by the series inverter, and the active power is transmitted to the dc terminals. The shunt inverter operates in such a way as to demand this de terminal power (positive or negative) from the line keeping the voltage across the storage capacitor $\mathrm{V}_{\mathrm{dc}}$ constant. Therefore, the net real power absorbed from the line by the UPFC is equal only to the losses of the inverters and their transformers [18]. The remaining capacity of the shunt inverter can be used to exchange reactive power with the line so as to provide a voltage regulation at the connection point. The two VSI's can work independently of each other by separating the dc side. Thus the shunt inverter is operating as a STATCOM (Static Synchronous Compensators) that produces or absorbs reactive power to regulate the voltage magnitude at the point of connection. "Instead, the series inverter is operating as SSSC (Static Synchronous series compensators) that generates or absorbs reactive power to regulate the current flow, and hence the power flows on the transmission line."[18]

Control strategy for FACTS controllers may be designed by using intelligent, adaptive digital controllers based on measured information obtained from wide-area networks. In order to ensure the security of power-system operation by coordination of multiple FACTS controllers in the same 
system as well as in the adjacent systems it is imperative that the system be investigated extensively.

\section{Facts Controllers Locations}

Ideally FACTS devices should be connected to the power system in a proper way because improperly placed FACTS controllers fail to produce optimum performance and can even be counterproductive, that's why the placement of these devices is of a great importance. [19] Certain literatures reveal that connecting shunt FACTS device at the mid-point of the line, gives the maximum benefit to the line. This was based on the simplified model of the line neglecting the resistance and the capacitance of the line. However in recent works as in [20] at which practical cases are considered and the exact model of the line is taken into account, the results are much different from that calculated for the simplified model. In this work it's shown that the optimal location for the device is not in the mid-point of the line but rather slightly off-center of the transmission line gives the maximum benefit. And it has been stated that the best location from the center point depends on the line resistance and is linearly increased as $\mathrm{R} / \mathrm{X}$ ratio of the line is increased. In [19] where two types of FACTS devices are considered (SVC and STATCOM) which are both connected to the line in shunt. It has been shown that the location of the FACTS device is not fixed as stated by many researchers in case of uncompensated lines but their location changes with the change in the degree of series compensation. And it's almost linear with the degree of series compensation in increment and its location moves towards the generator side from the center point as the degree of series compensation is increased. In [21] it's stated that for an actual long transmission line model with a predefined direction of real power flow, shunt facts device needs to be allocated slightly off-center. Further the location of these devices depends on the amount of local load and through load and from transient stability point of view their location moves towards the sending-end, See figure 2.

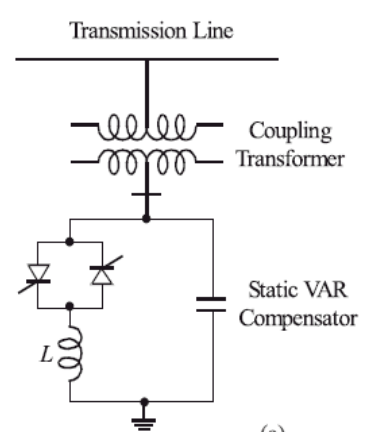

(a)

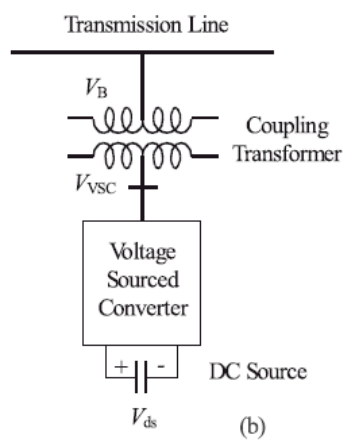

(b) (a) SVC connected to a transmission line, (b) STATCOM connected to a transmission line.

Fig. 2. The location of shunt connected FACTS devices

For series connected FACTS controller (such as TCSC), power flow control can not only be on the line in which it is connected, but also in the parallel paths (depending on the control strategies). Series connected devices is one of the most effective means to modify the grid [22]. Many have attempted series compensation in different lines, and for various compensations levels, and computed the actual change in transfer capacity as a result of the compensation and observe that power transfer capacity can be increased or decreased depending on the line selected for compensation.

\section{Location Criteria For The Device}

The locations of these devises are based on several criteria's which include for example, Sensitivity-Based approach, Artificial Intelligence methods, Point of Voltage Collapse method, Nodal analysis, Frequency response, stability index and Control theories. Generally, the location of FACTS devices depends on the objective of the installation. The optimal location can be guided by increasing system load ability [23],[24],[25] and [26], thus minimizing the total generation cost, and enhancing voltage stability [27]. FACTS devices can be placed in the power networks for different reasons and their locations can be determined by applying different techniques. For instance, FACTS devices can be used for voltage stability and reactive power compensations, controlling the power flow and enhancing the dynamic stability. There are several algorithms in use for this work, such as genetic algorithm (GA), Bee's algorithm (BA), Evolutionary programming and particle swarm optimization (PSO). It is much more complicated to place several types of FACTS devices and the location of each one in the system. One of the methods to find the best position for the FACTS devices and the best number of FACTS devices is the particle swarm optimization (PSO). In PSO first the bus data, line data, and number of FACTS devices are given as inputs, and then the initial population of individuals is created in normalized form so as to satisfy the FACTS device's constraints. After that each individual in the population, the fitness function is evaluated after simulating all possible single and multiple contingencies by using AC load flow.

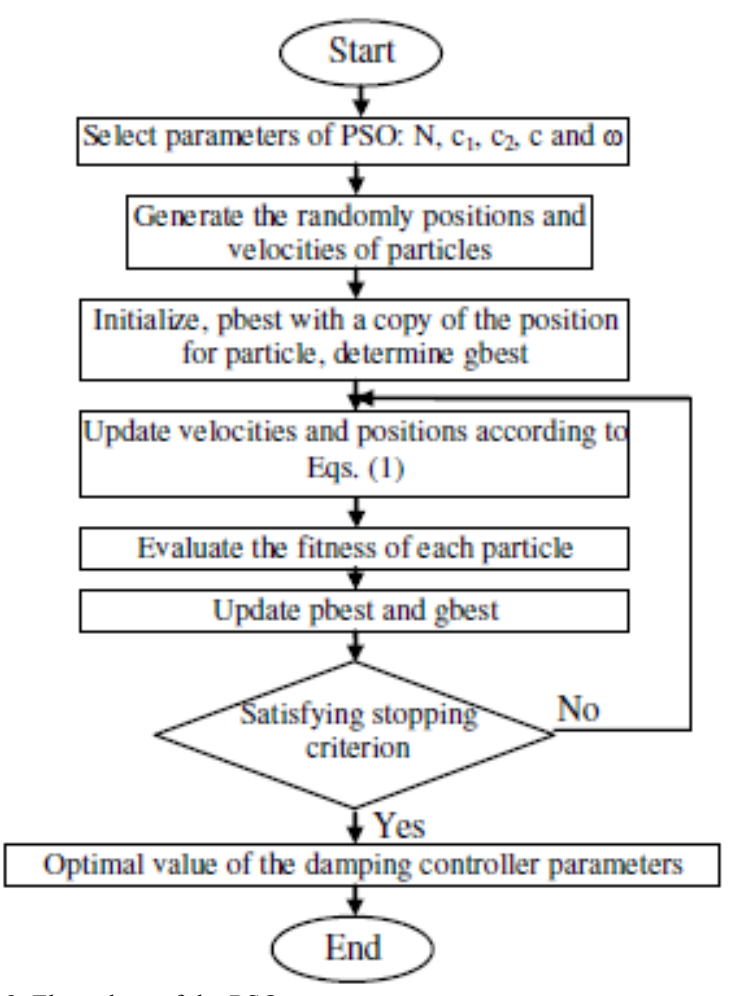

Fig. 3. Flow chart of the PSO. 
Then the velocity is updated and new population is created, if maximum iteration number is reached then the best individual's settings are printed if not, the same process is repeated as stated in [28]. PSO is a nature-inspired stochastic search algorithm, which can provide a solution in a reasonable time, near-optimal point figure 3 , shows a flow chart the PSO. This search algorithm is based on the knowledge gained by both the swarm and each individual, called a particle. Each particle represents a candidate solution of the optimum design problem in the swarm. Among the important features of the PSO algorithm are easy implementation, fewer adjustable parameters, suitable for the nature of the problem, efficiency in maintaining the swarm diversity for improvement of the particle information and simplicity and easy to coded. PSO is initialized with a group of random particles and searches for the optimal point by updating generations. Each iteration updated particles by the best values of itself and the swarm's.

Genetic Algorithms (GAs): are global search techniques. They can search several possible solutions simultaneously and they don't require any prior knowledge or special properties of the objective function. Moreover, they always produce high quality solutions and therefore, they are excellent methods for searching optimal solution in a complex problem. GA uses probabilistic transition rules, not deterministic rules. Is highly multi-direction, parallel and rather robust method in searching global optimal solution of complex optimization [29],

Bee Algorithm: This Artificial Bee Colony algorithm is a new population-based metaheuristic approach proposed by Karaboga [30]. This approach was inspired by the intelligent foraging behavior of honeybee swarm. It starts with initial population of scout bees which is generated from the number of FACTS devices the Type of FACTS devices and the possible location of these devices. Then the fitness computation process is carried out for each site visited by a bee by calculating the ATC. Then the bees that have the highest fitness are chosen as selected bees and sites visited by them are chosen for neighborhood search. And the size of neighborhood search did by the bees in the selected sites. Then the algorithm conducts searches around the selected sites based on size determined. And more bees are assigned to search in the vicinity of the best sites and the selection of the best sites can be made directly according to the finesses related to them. Then the remaining bees are sent for random search to find other potential sites. After that randomly initialized a new population and finds the best global points. [31][32]

One of other technique been used is a frequency response technique which has been discussed by[33] where he proposed that in order to reduce the damping power oscillations effect of the transmissions lines, frequency response can be used to installing locations and input control signals of FACTS-based stabilizers. Two types of frequency response has been discussed where it has two different transfer function need to be consider which is closed-loop and open-loop system. This method also requires analyzing the alternative locations in order to select the best one, the best input control signal and the best feedback signal. FACTS device such as TCSC was inserted into a determined location then the polar plots of each input control signal was analyze then select the best one. In this technique, the location for the FACTS devices been continuing changed randomly and new analysis were carried out.

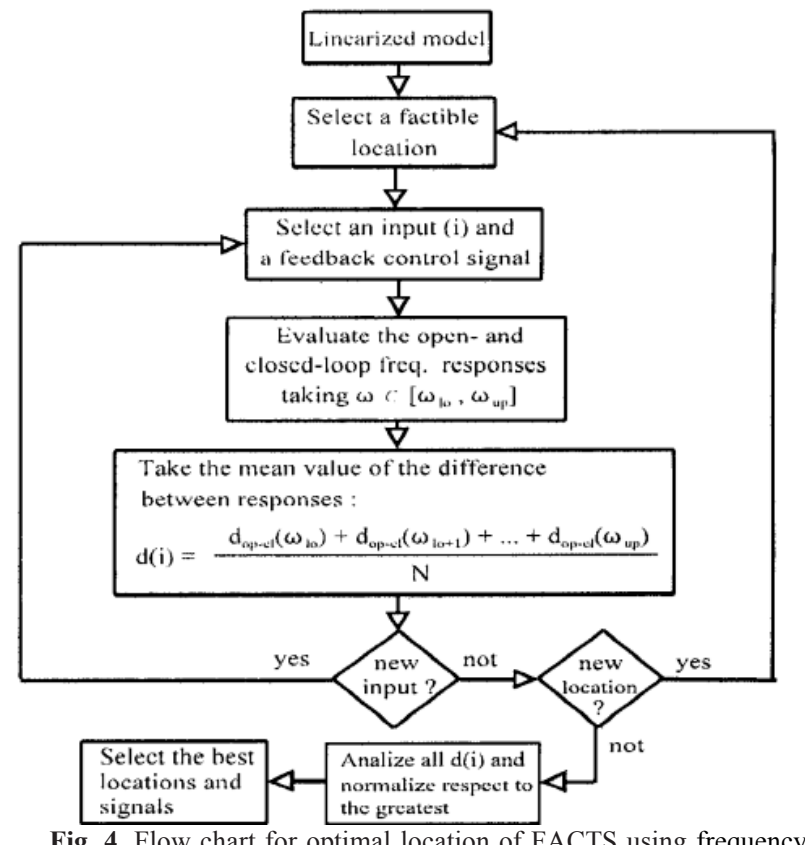

Fig. 4. Flow chart for optimal location of FACTS using frequency response

In the same year [24] have discussed other type of optimization technique called Genetic Algorithms (GA) where he focused on the optimal location of multi-type FACTS devices in a power system (TCSC, TCPST, TCVR and SVC). Meanwhile [34] proposed a genetic algorithm approach to determine the suitable types of FACTS devices and its optimal location in power systems. Other paper written by [35] has discussed on GA method of multi-type FACTS but with different device (TCSC, UPFC, TCPST and SVC) with aim to develop an algorithm to simultaneously find the real power allocation of generators and to find the type, rating and best location of FACTS controllers such that overall system cost, which includes the generation cost of power plants and investment cost of FACTS are minimized. A configuration of $n_{F}$ FACTS devices is defined with three parameters: the location of the devices, their types and their values. This technique starts with random generation of initial population followed by the selection. After that crossover and mutation are proceed until the best population is found. The advantage that has been describe for this technique were it is independent of the choice of the initial configurations, based on the mechanisms of natural selection, has possibility to converge prematurely to suboptimal solution and computationally simple and easy to implement. Below is the general flow chart for optimal location of FACTS using GA. Improvements of optimization techniques continue to expand and in year 2006 Low Discrepancy Sequence (LDS) method has been discussed where the main objective is to reduce the generation cost in the network. A. Alabduljabbar argue that GA technique did not show any details regarding the generation cost and the resulting saving, thus he proposed new technique, LDS[36]. This technique has been introduced and developed in the area of number theory for numerical integration purposes. LDS actually is a uniform scattering of points in a space bounded originally between 0 and 1 where it explores the search domain evenly. 


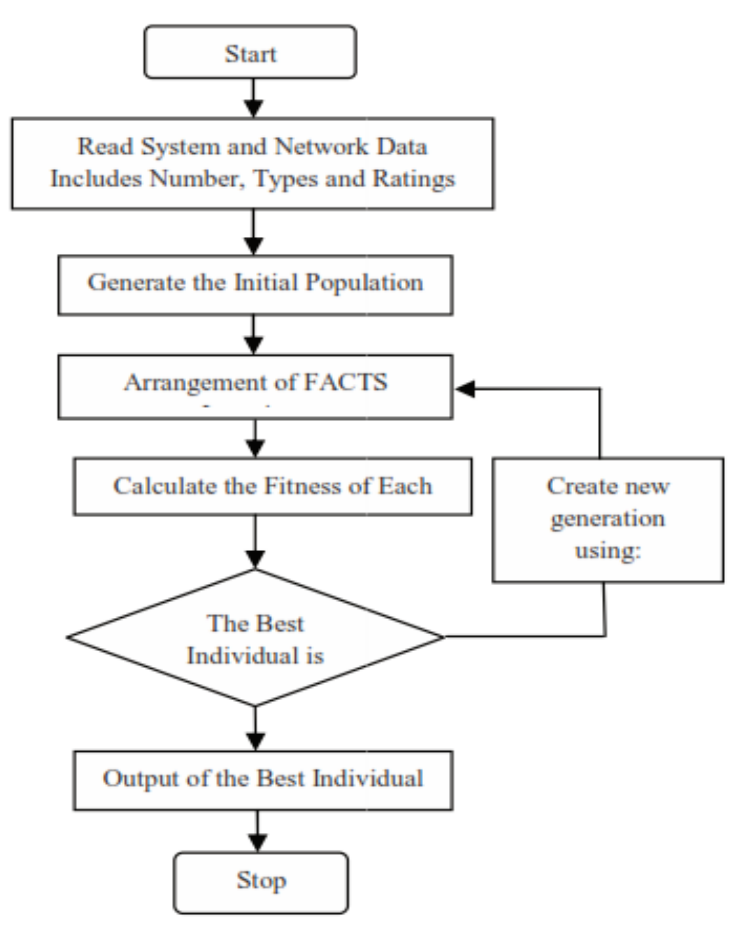

Fig. 5. Flow chart for optimal location of FACTS using GA.

The most widely used LDS point generators are: 1) Van der Corput sequence: It is a one dimensional LDS and it forms generally the basic sequence upon which the other generators depend; 2) Halton and Hammersley sequence; 3) Faure sequence and 4) Sobol sequence that mentioned by [36]. Among the advantages of this method is that it can lead to much smaller error and it use far less points from the search space to achieve the same better accuracy that GA method. Sensitivity Approach method (SA) has been discussed by [35] where it more focus on to find the optimal placement of TCSC and SSSC FACTS devices. These are popular methods of approximating the power system states after a change occur in the system. It is also based on reducing the nonlinear power flow equations into a linear system using the DC assumption. In SA also consist of line outage distribution factors (LODFs) where it can predict how the flow changes on a line when disturbance occur. LODF is a change in flow on lines as a percentage of the pre outage on another line. Results proved that the FACTS devices for TCSC was better to placed in a line having most negative sensitivity index however avoid placed it with generating transformers even though the sensitivity is the negative highest. Meanwhile for SSSC device, the optimal location is to place the SSSC in a line having highest absolute value of PI sensitivity with respect to injected phase angle.

\section{Conclusion}

The power industry is facing a number of challenges on the electricity infrastructure. These challenges necessitate the requirement of renewable sources for continuous operation during grid disturbances and thereby providing support for the network voltage and frequency. Some of the commonly used FACTS devices for this support include Static synchronous series compensator (SSSC), static synchronous compensator (STATCOM), interline power flow controller (IPFC), unified power flow controller (UPFC) and thyristor controlled series compensator (TCSC). This review presented the essential features of FACTS controllers and their potential to enhance system stability in power system network. In addition the location and feedback signals used for design of FACTS-based damping controllers were discussed. The coordination problem among different control schemes was also considered. Performance comparison of different FACTS controllers has been reviewed. Flexible AC Transmission System (FACTS) is a technology based solution that helps utility industry in dealing with changes in the power delivery business. The major driving force of FACTS technology is the development of power electric based systems which provide a dynamic control of the power transfer parameters transmission voltage, line impedance and phase angle without generation rescheduling or topological change. Three categories of FACTS controllers may be distinguished: Series controllers; Shunt controllers; Combined series-shunt controllers. New degrees of freedom are essentially introduced into the operation of power systems by the FACTS devices. This permits extra flexibility in the independent adjustment of certain system variables (such as power flows) which are normally not controllable. The controllable parameters FACTS devices can be differentiated by the manner in which they are realized electronically. Thus, devices exist which can control line series or shunt reactance, phase-shifting transformer angle, or combinations of these. Other devices inject controllable voltages in series or in parallel with the line being compensated. The optimal location of the shunt FACTS device is not fixed as reported by researchers in the case of uncompensated lines but it changes with the change in degree of series compensation. The deviation in the optimal location of the shunt FACT device from the center point of line depends upon the degree of series compensation and it increases almost linearly from the center point of the transmission line towards the generator side as the degree of series compensation $(\% \mathrm{~S})$ is increased. Both the power transfer capability and stability of the system can be improved much more if the shunt FACTS device is placed at the new optimal location instead of at the mid-point of the line. In this paper, a genetic algorithm based approach . 


\section{Reference}

1. A. Adamczyk, R. Teodorescu, R.N. Mukerjee, P. Rodriguez "Overview of FACTS Devices for Wind Power Plants Directly Connected to the Transmission Network"

2. J. Machowski, J.W. Bialek, J.R. Bumby, Power System Dynamics Stability and Control, John Wiley \& Sons, 2008

3. B. Sookananta, S. Galloway, G. M. Burt and J. R. McDonald, "The Placement of FACTS Devices in Modern Electrical Network", UPEC, 2006

4. H. Ren, D. Watts, Z. Mi, J. Lu, "A Review of FACTS' Practical Consideration and Economic Evaluation", Power and Energy Engineering Conference", APPEEC, 2009

5. M. Peikherfeh, M. Abapour, M. Parsa Moghaddam, Member, IEEE, A. Namdari "Optimal Allocation of FACTS Devices for Provision of Voltage Control Ancillary Services" 978-1-42446840-9/10/\$26.00 (C) 2010 IEEE

6. X.-P. Zhang, C. Rehtanz, B. Pal, Flexible AC Transmission Systems:Modelling and Control, Springer, 2006, Berlin

7. V. K.B Chennapragada S. B. S Kotamarti. V. H.Pindiprolu. "power system operation and control using fact devices" 17th International Conference on Electricity Distribution Barcelona, 1215 May 2003

8. F.D. Galiana, K. Almeida, M. Toussaint, J. Griffin, D. Atanackovic, B.T. Ooi, D.T. McGillis "Assessment and control of the impact of facts devices on power system performance" IEEE Transactions on Power Systems, Vol. 11, No. 4, November 19961931

9. W. Qiao, R. G. Harley, and G. K. Venayagamoorthy, "Effects of FACTS Devices on a Power System Which Includes a Large Wind Farm" National Science

10. Foundation, Washington, DC, USA, under grant ECS 0524183 and the Duke PowerCompany, Charlotte, North Carolina, USA.142440178X/06/\$20.00 C2006 IEEE

11. A. Moawwad, V. Khadkikar, and J. L. Kirtley,Jr., "Photovoltaic Power Plant as FACTS Devices in Multi-Feeder Systems"

12. L. Gyugyi, K. K. Sen, and C. D. Schauder, "The interline power flow controller concept: a new approach to power flow management in transmission systems," IEEE Trans on Power Delivery, vol.14, no.3, pp.1115-1123, Jul 1999.

13. A.K.Chakraborty, S. Majumdar, P.K. Chattopadhyay, C. Nandi "Active Line Flow Control of Power System Network with FACTS Devices of choice using Soft Computing Technique" International Journal of Computer Applications (0975 - 8887)Volume 25- No.9, July 2011

14. S. Haddad, A. Haddouche, and H. Bouyeda "The use of Facts devices in disturbed Power Systems-Modeling, Interface, and Case Study" International Journal of Computer and Electrical Engineering, Vol. 1, No. 1, April 2009

15. G. Andersson, L Angquist, M. Ghandhari, M. Noroozian, 1997, "Use of UPFC for optimal power flow control ", IEEE Transactions on Power Delivery, Volume: 12 Issue: 4 , Page(s): 1629-1634.

16. C.D.Schauder, , L. Gyugyi, M.R. Lund, D. M. Hamai, T. R. Rietman, D. R. Torgerson, and A. Edris,.:Operation of the unified power flow controller (UPFC) under practical constraints', IEEE Trans., 1997, PD-, (PE-51 1-PWRD-0-11-1996)

17. L. GYUGYI,.: 'A unified power flow control concept for flexible AC transmission systems', IEE Proc. C, 1992, 139, (4) pp. 323-333

18. L. $\mathrm{Xu}$ and V.G. Agelidis, "Flying Capacitor Multilevel PWM Converter Based UPFC', IEE Proc. Of Electronic Power Application,Vol. 149, No. 4, July 2003. Page(s) 304-310.

19. P.S.Vaidya, V.P.Rajderkar, "Optimal Location of Series FACTS Devices for Enhancing Power System Security”, Fourth International Conference on Emerging Trends in Engineering \& Technology, pp 185- 190, 2011.
20. V. Gupta "Study and Effects of UPFC and its Control System for Power Flow Control and Voltage Injection in a Power System" Vibhor Gupta / International Journal of Engineering Science and Technology Vol. 2(7), 2010, 2558-2566

21. P. R. Sharma, A. Kumar and N. Kumar "Optimal Location for Shunt Connected FACTS Devices in a Series Compensated Long Transmission Line" Turk J Elec Engin,VOL.15, NO.3 2007, c T"UB'ITAK

22. M.Kowsalya, K.K.Ray, and D.P.Kothari "Positioning of SVC and STATCOM in a Long Transmission Line" International Journal of Recent Trends in Engineering, Vol 2, No. 5, November 2009150

23. S. P. R. N. Patel "Improving Power System Transient Stabilitywith An Off-Centre Location Of Shunt Facts Devices" Journal of ELECTRICAL ENGINEERING, VOL. 57, NO. 6, 2006, 365-368

24. R. Rajaraman, F.Alvarado, A. Maniaci, R. Camfield, and S. Jalali "Determination of location and Amount of Series Compensation to Increase Power Transfer Capability"IEEE Transactions on Power Systems, Vol. 13, No. 2, May 1998

25. M. A. Abido "power system stability enhancement using facts controllers: a review" The Arabian Journal for Science and Engineering, Volume 34, Number 1B

26. S. Gerbex, R. Cherkaoui, and A. J. Germond, "Optimal Location of Multi-Type FACTS Devices in a Power System by Means of Genetic Algorithms", IEEE Trans. PWRS, 16(3)(2001), pp. 537544.

27. J. Hao, L. B. Shi, and Ch. Chen, "Optimizing Location of Unified Power Flow Controllers by Means of Improved Evolutionary Programming", IEE Proc. Genet. Transm. Distrib., 151(6)(2004), pp. 705-712.

28. F. G. M. Lima, D. Galiana, I. Kockar, and J. Munoz, "Phase Shifter Placement in Large-Scale Systems via Mixed Integer Linear Programming", IEEE Trans. PWRS, 18(3)(2003), pp. 1029-1034.

29. N. K. Sharma, A. Ghosh, and R. K. Varma, "A Novel Placement Strategy for FACTS Controllers", IEEE Trans.PWRD, 18(3)(2003), pp. 982-987.

30. S. Sutha, and N. Kamaraj "Optimal Location of Multi Type Facts Devices for Multiple Contingencies Using Particle Swarm Optimization" World Academy of Science, Engineering and Technology 462008

31. S. Gerbex, R. Cherkaoui, and A. J. Germond, "Optimal Location of Multi-Type FACTS Devices in a Power System by Means of Genetic Algorithms" IEEE TRANSACTIONS ON POWER SYSTEMS, VOL. 16, NO. 3, AUGUST 2001537

32. D. Karaboga. An idea based on honey bee swarm for numerical optimization. Technical Report TR06, Computer Engineering Department, Erciyes University, Turkey, 2005.

33. R.Mohamad Idris, A.Kharuddin, M.W.Mustafa "Optimal Choice ofFACTS Devices for ATC Enhancement Using Bees Algorithm" Electrical Power Engineering Universiti Teknologi Malaysia Skudai, Johor Malaysia

34. L.J. Cai, I. Erlich and G.Stamtsis, "Optimal Choice and Allocation of FACTS Devices in Deregulated Electricity Market using Genetic Algorithms" 0-7803-8718-X/04/\$20.00@2004IEEE.

35. Juan M. Ramirez, "A Frequency Response Technique to Allocate Facts Devices”, IEEE, pp 1530-1535, 2001.

36. Cai L. J. and Erlich I., "Optimal Choice and Allocation of FACTS Devices Using Genetic Algorithms", IEEE Trans of PowerSystem,pp.1-6

37. Ayman A. Alabduljabbar, J. V. Milanovi, "Generation Costs Reduction Through Optimal Allocation of FACTS Devices Using Low Discrepancy Sequences”, IEEE, pp946-951, 2006. 